\title{
Call for Papers
}

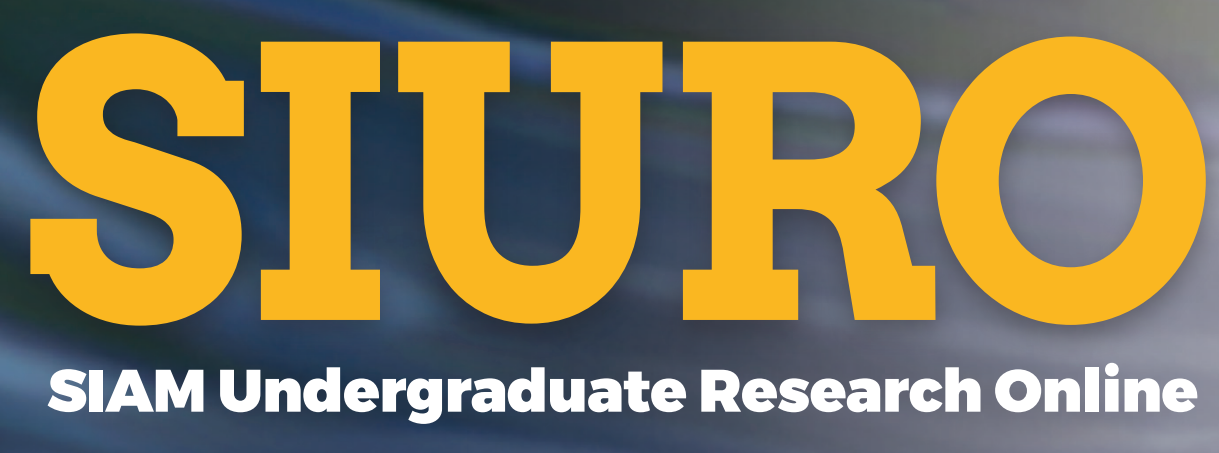

Publishing outstanding research in applied and computational mathematics by undergraduates

\author{
Editor-in-Chief \\ Luis Melara, Shippensburg University \\ LAMelara@ship.edu
}

\section{Associate Editors}

Brittany Bannish, University of Central Oklahoma
Julie Blackwood, Williams College
Erika Camacho, Arizona State University
John Carter, Seattle University
Tim Chartier, Davidson College
Maria Emelianenko, George Mason University
Jennifer Fowler, Lamar University
Sommer Gentry, United States Naval Academy
Jana Gevertz, The College of New Jersey Michele Joyner, East Tennessee State University Kathleen Kavanagh, Clarkson University Karin Leiderman, Colorado School of Mines Nathan Tintle, Dordt College Joanna Wares, University of Richmond Abdul-Aziz Yakubu, Howard University Lizette Zietsman, Virginia Tech

SIAM Undergraduate Research Online is an open-access publication devoted to undergraduate research in applied and computational mathematics. Topics include subjects such as analysis, discrete mathematics, statistics, operations research, optimization, dynamical systems, modeling, and computation. Applications come from areas such as the physical, life, financial, and management sciences and engineering.

Authors may take advantage of the web-based nature of the publication by submitting supplemental files that include animations, software demonstrations, and innovative graphics.

\section{Submit your paper}

SIURO papers are written by undergraduates as part of their undergraduate education. Student authors prepare and submit the paper, correspond with an Associate Editor, have the paper read by outside referees, and respond to the referees. SIURO provides articles on applied and computational topics that are accessible to undergraduate students. For faculty advisors and mentors, the publication provides models of outstanding undergraduate research.

Papers are posted online as they are accepted. The turnaround in refereeing papers is very short. Access is free and open to all.

Learn more: www.siam.org/Publications/SIURO 